\title{
Original Artide
}

\section{Studying Knowledge, Attitude and Behavior of Breast Cancer Screening Methods among Behshahr Dwelling Women}

\author{
Seyed Abdolhasan Naghibi ${ }^{1} \quad$ *Davood Shojaizadeh ${ }^{2} \quad$ Ali Montazeri $^{3} \quad$ Jamshid Yazdani Cherati $^{4}$
}

1- Health Sciences Research Center, Faculty of Health, Mazandaran University of Medical Sciences, Sari, Iran

2- Professor, Department of Health Education and Promotion, School of Public Health and Institute of Public Health Research, Tehran University of Medical Sciences, Tehran

3- Professor, Mental Health Group, Health Metrics Research Center, Iranian Institute for Health Sciences Research Tehran, Iran

4- Assistant Professor, Department of Biostatistics, Health Sciences Research Center, Faculty of Health, Mazandaran University of Medical Sciences, Sari, Iran

*Shojaei@yahoo.com

\section{Abstract}

Background and purpose: Breast cancer is the most prevalent cancer among all widespread cancers worldwide. After lung cancer, breast cancer is the main cause of death among women. One of the best ways to detect this disease early is to do screening. This study has been done to analyze the knowledge, attitude, and behavior of women regarding the breast cancer screening methods.

Materials and Methods: The study is of cross-sectional descriptive type. The participants were 500 Behshahr dwelling women above 20 years old selected based on cluster sampling. The instrument used was a 34-item questionnaire to investigate the knowledge, attitude, and behavior of the women. The data has been analyzed through inferential statistical methods.

Results: The participants' age mean was 35.16. The average knowledge score of the disease and screening methods was 1.3 and 54.6. The average attitude score of was 82.5. Regarding behavior, 13.1 percent do regular self-examination, and 15.2 percent do regular clinical examination. 16.7 percent of women have one experience of doing mammography. In the present study, there was a significant relation among knowledge, attitude and behavior.

Conclusion: Since the knowledge of women was at average level and the behavior of using the screening methods was weak, planning to enable and motivate women to use the screening methods is highly emphasized. [*Naghibi A. Shojaizadeh D. Montazeri A. Yazdanicherati J. Studying knowledge, Attitude \& Behavior of Breast Cancer Screening Methods among Behshahr Dwelling Women. IJIIS 2013; 1(2):75-82] http://jhs.mazums.ac.ir

Key words: Knowledge, Attitude, Behavior, Screening, Breast Cancer 


\section{Introduction}

Breast cancer is the most prevalent cancer among all widespread cancers in the world. After the lung cancer, breast cancer is the main cause of death among women $(1,2)$. In the developed countries, one woman out of 8 to 12 women is afflicted with this cancer (3). Breast cancer in Iranian women is still in the front rank (4). According to the report of the ministry of health in 1387,8424 people have been afflicted with breast cancer, and the crud rate of the disease has been 24.66 thousands percent and the age specific rate has been reported 33.21 thousands percent(5). If breast cancer is identified early, more than 90 percent of the afflicted people can be cured (6). One of the best ways of early detection of the disease is screening (7). The screening ways of disease identification include: breast self examination, clinical breast examination by the doctor or a health visitor, and mammography (1). Breast self examination is a cheap and simple way and leads to the individual's of the breast cancer (8). In clinical breast examination, about 60 percent of the cancer causes are identified. The recent studies show that the clinical breast examination has about 54 percent sensitivity and the property of $94 \%(1)$. Mammography is the most effective way of early detection of breast cancer (9). Montazeri has reported that the Iranian women's self examination is 17 percent (1). In Nigeria, it was reported 24 percent and in Malaysia 17 percent $(10,11)$. The studies of CBE in Iran was 4-20 percent, $(12,13)$ and in Turkey it was 14,1 percent(14). According to the studies, in Iran the mammography rate was $3-6,5$ percent $(15,16)$ and in Malaysia was 13.6 percent(17). Most studies in Iran reported the rate of Iranian women's of the cancer screening ways relatively low, in that, in the study of Salimpormehr, the of women was 33.3 percent, in that of Dadkhah, 14\%, in that of Mazloomi it was good at 38.3 percent $(12,18,19)$. In the study of Montazeri, 64 percent of women have stated the unfamiliarity of the way to do it as the reason of not performing the breast self examination. Also in many studies, the rate of Iranian women's has been reported positive. Rate of women in the study of Naghibi was reported positive at $76.4 \%$, in Raesi $72.6 \%$ and in AlaieNezhad $78 \% \quad(20,21,22)$. Since using screening ways has a significant role in preventing and controlling the women breast cancer, women and attitude towards early detection plan of breast cancer to perform the health Behavior is necessary. This study has been done to investigate the, attitude and Behavior of Behshahr women regarding the screening ways of breast cancer.

\section{Materials and Methods}

The study is of the sectional descriptive type. The participants were 500 women of Behshahr aged more than 20 years selected based on cluster sampling. Sampling started after 10 blocks from the main square of the city to four directions, east, west, south, and north. The samples are divided equally in 4 directions. The material was a 34-item questionnaire including 8 questions for demography, 10 questions for of the disease and the screening way of breast cancer, 10 
questions for women attitude towards the screening way of breast cancer, 6 questions for Behavior of screening ways in the study samples. The options of the questionnaire for of the study samples include: yes, no and I don't know, and the scores are 1,-1,0 respectively. In the Likert-scale questions with 5 options for attitude, the options based on the type of questions (direct or reverse) include: Strongly agree 5, Agree 4, neither agree nor disagree 3, Disagree 2, strongly disagree 1. In order to study the Behavior of screening ways of breast cancer which includes breast self examination, clinical examination by doctor and health visitors, and mammography, the yes, no options and 1,0 scores were utilized. For the validity of the questionnaire, expert validity has been used. The reliability was estimated through Cranach's Alpha reliability. The estimation of from the questionnaire has been $78 \%$, of attitude $81 \%$ and of Behavior $83 \%$. The data collected was calculated through SPSS 19. Software and through descriptive statistics; and to study the effect of other variables regression logistics and Pearson correlation were utilized. Finally, the one tail analysis of variance was analyzed.

\section{Results}

The results of the study show the average age of the women under the study was 35.16, concerning marital status, $85.7 \%$ were married and $7.4 \%$ were single. Most of the women, $79.9 \%$ were housewives, $11.2 \%$ had jobs. The average age of starting their period was 13.75 \pm 1.48 . The average age of their first pregnancy was $20.9 \pm 4.7$, and the average age of menopause was 48.51 \pm 5.3 . Regarding education, $13.9 \%$ of the women have education at 3rd guidance school, 55.45 at diploma and super-diploma, and $13.5 \%$ above super-diploma. 9.6\% had the record of breast diseases. Moreover, $8 \%$ of the women had the record of benign breast cancer among their first- degree relatives, $12 \%$ of women had record of breast cancer in the second-degree relatives. The results of the study show that the average of women of the disease and breast cancer screening ways as $54.6 \pm 1.3$ with confidence interval of $95 \%$ has been (51.98, 57.25). In this study there was no positive relationship between and women demographic properties. Based on the results of the study, there was a significant relationship between and the record of breast diseases in people $(\mathrm{P}=0.05)$. The women with previous record of breast diseases has been $62.5 \pm 1.3$, and women without record of breast diseases has been $53 \pm 2.3$. By Pearson test, there was a positive relationship between the two variables, and women attitude, in that the increase in is effective in positive attitude $(\mathrm{P}<0.0001)$. Based on the regression logistic test, there was a meaningful relationship between and behavior of women in breast self examination, in that with one score increase in awareness, there will be $2 \%$ chance of doing self examination. Also, regression logistic test shows a meaningful statistical relationship between and behavior of breast clinical examination, in that with one score increase in awareness, $1.3 \%$ chance of doing clinical examination increases (table 1). Based on the results of the study, the average score of attitude $82.5 \pm 0.5$ with confidence interval of 95 has been $(81.42,83.58)$. For women's attitude towards the screening ways, $86.4 \%$ were strongly agree and agree answering the item "I believe through screening any kind of benign lump (mass) can be identified and cured timely". Answering the item "I believe 
the fear from identification hinders the screening", $89.2 \%$ were strongly disagree and disagree. Answering the item "I believe doing screening ways should be taken seriously", $74.7 \%$ were strongly agreed and agree. Table 2 shows the number and percent of every option related to women attitude towards the cancer screening ways. Regarding the relationship between attitude and variables of demography, there was a meaningful statistical relationship only between attitude and literacy. People with low literacy level, the attitude score was much lower. Using one tail variance analysis $\mathrm{P}=0.038$ with Benfroni's post-test showed that the women with low literacy level had lower attitude scores compared with others. Considering the relationship between attitude and Behavior of using screening ways, the results of the study showed that there was a meaningful relationship between attitude and breast self examination. Through regression logistic test, for every one score increase in attitude, 3\% chance of doing breast self examination increases There was also a meaningful statistical relationship between attitude and breast clinical examination. Based on the regression logistic test, with one score increase in attitude, the chance of clinical examination increases to $4 \%$, In addition, using regression logistic, there was a meaningful relation between attitudes and doing mammography. With one score increase in attitude, the chance of doing mammography increases to $2.3 \%$. The results of the study show the relationship between the Behavior of using screening ways and variables of demography and other variables. There was a positive relationship between the Behavior of breast self examination of married $(\mathrm{P}<0.029)$ and record of breast diseases in individuals $(\mathrm{P}<0.0001)$. There was a positive relationship among the Behavior of mammography of educated women $(\mathrm{P}<0.013)$ and people with record of breast diseases $(\mathrm{P}<0.001)$ and people with record of disease in relatives $(\mathrm{P}<0.023)$. Using regression logistic test, there was a meaningful relation between the variable of mammography and age, in that with one year increase in age, the chance of doing mammography increases to $4 \%$ (Table 1).

Table 1. The percent of reply to the options of attitude in relation with the breast screening ways of women under the study in 2012( $\mathrm{N}=500)$

\begin{tabular}{|c|c|c|c|c|c|}
\hline variable & recreation & SE & $\begin{array}{c}\text { variable } \\
\text { independent }\end{array}$ & $\begin{array}{c}\text { p- } \\
\text { value }\end{array}$ & Odds \\
\hline Knowledge & 0.2 & 0.003 & $\begin{array}{c}\text { self } \\
\text { examination }\end{array}$ & 0.0001 & 0.02 \\
\hline Knowledge & 0.013 & 0.003 & $\begin{array}{c}\text { clinical } \\
\text { examination }\end{array}$ & 0.0001 & 0.013 \\
\hline Attitude & 0.033 & 0.008 & $\begin{array}{c}\text { self } \\
\text { examination }\end{array}$ & 0.001 & 1.034 \\
\hline Attitude & 0.4 & 0.009 & $\begin{array}{c}\text { clinical } \\
\text { examination }\end{array}$ & 0.0001 & 1.041 \\
\hline Attitude & 0.23 & 0.001 & mammography & 0.041 & 1.023 \\
\hline
\end{tabular}


Table 2. The Behavior of breast cancer screening ways in women under the study in $2012(\mathrm{n}=500)$

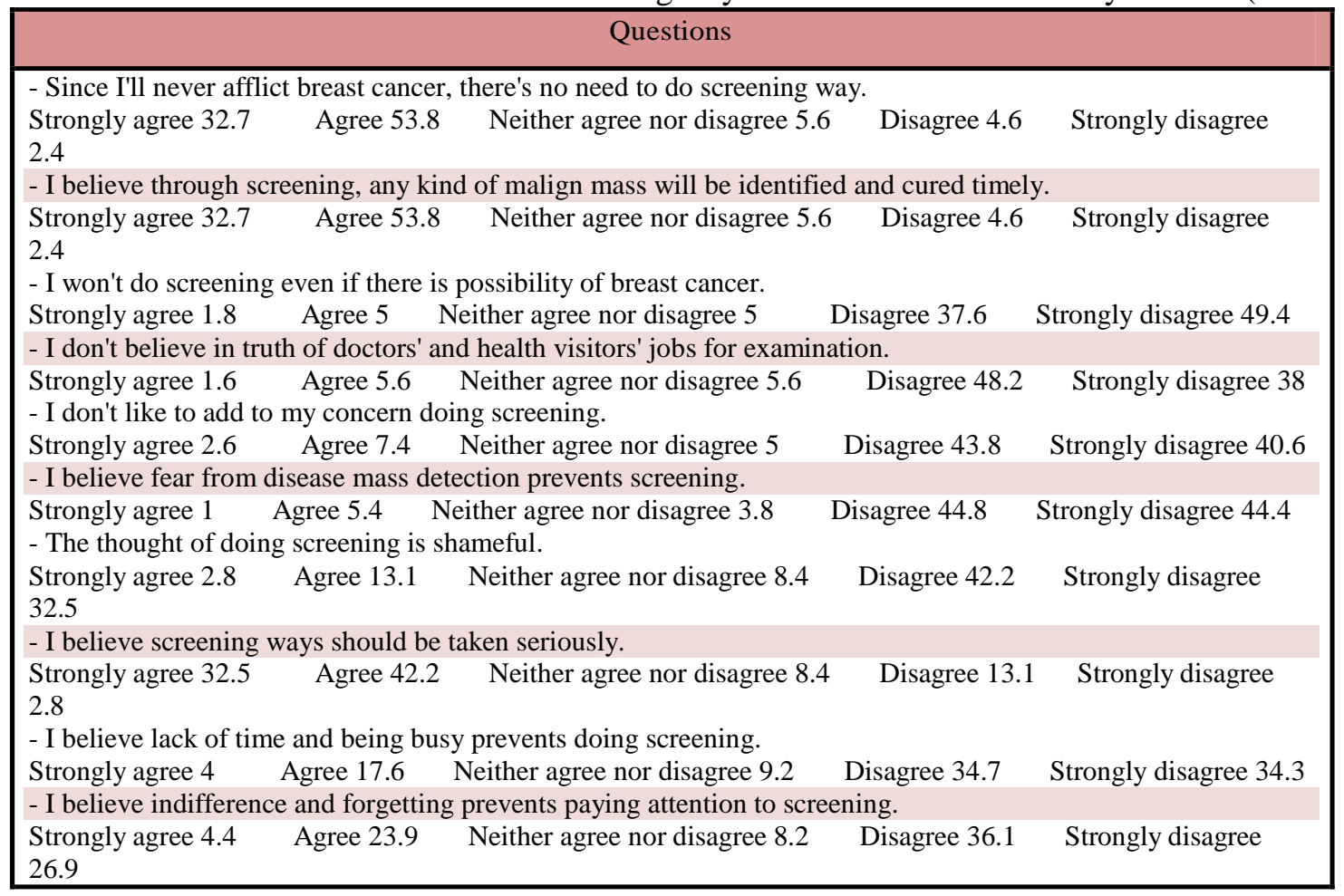

The results of the study about using the screening ways show that they have $53.4 \%$ experience of self examination. That only 13.1 $\%$ of them do the self examination regularly.
Also, $32.1 \%$ of women had record of clinical examination that only $15.2 \%$ did it regularly and annually. $16.7 \%$ of women had once experience of doing mammography (Table 3).

Table 3. Analyzing recreation variable effect The Behavior of breast cancer screening ways in women under the study in $2012(n=500)$

\begin{tabular}{lcc}
\hline \multicolumn{1}{c}{ Questions } & percent & number \\
\hline Record of doing breast self examination & & \\
Yes & 53.4 & 268 \\
No & 46.6 & 234 \\
The time interval of breast self examination & & \\
Regular & 13.1 & 64 \\
Irregular & 39.8 & 200 \\
The record of breast clinical examination & & \\
Yes & 23.1 & 161 \\
No & 69.7 & 341 \\
The time interval of clinical examination & & \\
Less than 1 year & 15.2 & 76 \\
1-3 years 17.2 & 17.2 & 88 \\
The record of doing mammography & & \\
Yes & 16.7 & 84 \\
No & 82.5 & 414 \\
The time interval of mammography & & \\
Less than 1 year & 6 & 30 \\
1-3 years & 6.4 & 32 \\
More than 3 years & 4.5 & 21 \\
\hline
\end{tabular}




\section{Discussion}

In this study, knowledge, attitude and Behavior of women were studied. Based on the results of the study, the average score was 54.6 \pm 1.3 . The rate of women has been at average level. These results were consistent with the study of Yavari, Naghibi and Godazandeh. In Montazeri's study, 64\% of Iranian women announced the how to do self examination as the reason of not doing it. In Harrirchi's study, the and Iranian women's attitudes towards the early detection of breast cancer was relatively at appropriate level, (24) while SIM reported low degree of individual of the danger causes, screening and disease cure in Asian women(25). In the study of Jahan, $69.7 \%$ of the participants had no about self examination (26). Based on the results of the present study and other similar studies in Iran, it seems that Iranian women's about the screening is relatively low. In this study, there was no positive relationship between and demographic variables. These results are similar to the Naghibi's research (20), but in the study of Godazandeh, Dadkhah, and Besharat, there was a positive relation among age, literacy, marital status, and awareness $(23,27,18)$. In the present study, there is a meaningful relation between only with one's affliction of breast benign diseases. These results are similar to the study of Ziaee far and Bonabian (7). In this study, there was a positive relation between and women attitude towards screening ways, and Behaviour of breast self examination and clinical examination by a doctor that the results conform the study of Naghibi, Ghazanfari $(20,16,7)$ in attitude aspect, and with the study of Farshbaf, Godazandeh, and
Ghazanfari in Behaviour aspect(15,16,23). In Yousuf.SA study, there is a correlation between scores and age, education, family experience and marital status (29). In the present study, the average attitude score has been $82.5 \pm 0.5$. The women's attitude towards the breast cancer screening ways has been positive. These results were similar to the studies of Naghibi, Abedzadeh, Reisi and Khani. Regarding the relationship between attitude and demographic variables, the only relation was with literacy which was consistent with the studies of Ghazanfari and Reisi(16,21). $90 \%$ of women's attitude was positive in Sara Gilani's study in Pakistan and in Rasmavatinh's study, it was $73.3 \%$. (33) In the present study, the Behavior of regular breast self examination of women has been $13.1 \%$; the regular and annual Behavior of clinical examination was $15.2 \%$; and $16.7 \%$ of women had the record of mammography. The Behavior of breast self examination has been reported satisfactory in the study of Farshbaf as $1.8 \%$, Abedzadeh $19.3 \% \quad(15,20)$. In Montazeri's study, the regular self examination of Iranian women was reported as 17\%, in Pavsu's in Malaysia $19 \%$ and Ozkan A.'s in Turkey 32.7\%. The Behaviour of clinical examination in Salimipormehr's study has been $4.7 \%$, in SoltanAhmadi's $21.5 \%$ and in Naghibi's $20.7 \%$. In the present study, $16.7 \%$ of women under the study have had once experience of doing mammography. In this study, there was a relation between age, and mammography which is consistent with Godazandeh's study (23). Due to the difference and dissimilarity in the results of rate, attitude and screening Behavior in Iranian researchers' articles, it can be related 
to doing the study in various provinces and cities along with limited samples, using different instruments for assessing awareness, attitude, Behavior, nonstandard measuring devices and different scoring ways. Based on the results of the study, the women of disease and breast cancer screening ways was at average level, but the women's Behavior in using the screening ways has been weak. On the other hand, the most important strategy in preventing and decreasing death by women cancer is using screening ways for this disease. Therefore, it is necessary to act in total programming in order to upgrade the society's general and enabling and motivating women in using screening ways regularly (self examination, clinical examination, mammography).

\section{References}

1. Montazeri A, et al. Breast cancer in Iran: need for greater women awareness of warning signs and effective screening methods. Asia Pac Fam Med, 2008; 7(1),6.

2.Mokhtari L, Baradaran Rezaee M, Mohammadpour Asl A, Mousavi SM. Health Beliefs about Mammography and Clinical Breast Examination among Female Healthcare Providers in Tabriz Health Centers. Iran Journal of Nursing (IJN),2011;24(71):63-73.

3.Majidzade.k;Moradi.SH.M;Abdoli.N, Ansar.M Clinical Characteristics and Risk Profile of Individuals Referred to Familial Breast Cancer Clinic of Tehran: the Necessity of Genetic Counseling JAUMS,2009;7(1).

4. Medical education \& health therapeutic ministry, cancerous cases record countrywide report, 2007.

5. Medical education \& health therapeutic ministry, cancerous cases record countrywide report, 2008.

6.Karimy M, M.H.M., The Effect of Education, Based on Health Belief Model on Breast SelfExamination in Health Liaisons of Zarandieh
City. Persian. Journal. zahedan university of medical sciences and health services, 2008;10(4):281-289.

7.Banaeian sh, Kazemian A, Kheiri S, Analysis of knowledge, attitude \& performance of women referring to Brojen city health \& therapeutic centers concerning breast cancer screening \& its effective factors, 2005

8.Parsa, P. kandiah.M .parsa.N Factors associted with breast self-examination among Malaysian women teachers, East mediterr health J.2011 Jun :17 ( 6):509-16

9.Naghibi Abolhassan. Shojaeezade Davoud MontazeriAli yazdani. Jamshid. Early detection of Breast Cancer among women in Mazandaran, Iran.IJOHS,2013;1(1):44-49.

10.Olugbenga-Bello A, Oladele EA, Bello TO, Ojo JO, Oguntola AS. Awareness and breast cancer risk factors: perception and screening practices among females in a tertiary institution in Southwest Nigeria. Niger Postgrad Med J,2011;18(1):8-15.

11.Loh SY, Chew S. Awareness and practice of breast self examination among malaysian women with breast cancer Asian Pac J Cancer Prev,2011;12(1):199-202.

12.SalimiPormehr S, Kariman N, Sheykhan Z, AlaviMajd $H$. Investigation of Breast Cancer Screening Tests Performance and Affecting Factors in Women Referred to Ardebil's Health and Medical Centers. Journal of Ardabil University of medical sciences,2009; 10(4):310318

13.Laluii A, Kashanizadeh N. Knowledge of women about their breast examination referred to Gynecologic Clinic of Baghiatolah and Najmeh hospitals, Rehabilitation,2006;7(2):25.

14.Camo, Gümüs AB. Breast cancer screening behavior in Turkish women: Relationships with health beliefs and self-esteem, body perception and hopelessness. Asian Pac J Cancer Prev,2009;10(1):49-56.

15.Farshbaf khalili A, Shahnazi M, Ghahvechi A, Torabi sh, breast cancer screening methods status $\&$ its effective factors in women referring to Tabriz health \& therapeutic center, nursing research.2009; 4(12),(13):27-38.

16.Ghazanfari Z, Mohammad alizade. S, Ezattalab F," Analyzing the knowledge, attitude \& performance of women working in chalous regarding breast cancer prevention, Yazd Saddoqi 
medical science \& health therapeutic service journal 106,2005;14(2):44-50.

17.Parsa P, Kandiah M. Predictors of adherence to clinical breast examination and mammography screening among Malaysian women. Asian Pac J Cancer Prev,2010;11(3):681-8.

18.Dadkhah B, Mohammadi M. Knowledge, attitude and practice among women in Ardebil about breast self examination. Journal of Ardebil University of medical sciences.2002;2(5):14-20.

19.Mazlumi S, et al. Effect health education of knowledge attitude behavior women teacher about Breast cancer in Yazd journal brigand university of medical silences,2005;13(9).

20.Naghibi S A, Analyzing the knowledge, attitude \& performance about breast self examination in makou- based female auxiliary nurses, health science \& health faculty research institute journal, D.A.P, Tehran,2009;7(2).

21.Reiesy M. et al. Knowledge attitude, behavior women, worker in health center university of medical Esfahan journal re search health system, 2010;7(2).

22.Aalaeinejad F, Abbasian M, Delverianzade M, Analyzing the knowledge, attitude \& performance of health care providers skill in Shahroud about breast self- examination, Shahroud medical science \& health services university knowledge \& health journal, 2007;2(2):23-27.

23. Godazandeh GH, et al. knowledge and practice in women over 15 years old about breast cancer in Sari, Journal of Mazandaran University of Medical Sciences, 2004;16(5).

24.Harirchi I, et al. Early detection for breast cancer in iran. Asian Pac J Cancer Prev,2009;10(5):849-51.

25.Sim HL, Seah M, Tan SM Breast cancer knowledge and screening practices: a survey of 1,000 Asian women Singapore Med J,2009;50(2):132-8.

26. Jahan S, Abdullah M. Alsaigul, Muzamil H.Abdelgadir. Breast cancer, knowlge attitude and practices of breast self examination among woman in Qassim region of Saudi Arabia, 2006.

27.besharat,S. et al. study knowledge about breast self examination worker, and, women ,referred to health and medical center dezyani in gorgon, 2004;7(2).

28.ziaeefard Z. et al. knowledge of breast self examination and mammography women marred over 20 years old referred to health center in south Iran a journal of Jahrom university medical science, 2011;10(2).

29. Yousuf SA, Al Amoudi SM, Nicolas W, Banjar HE, Salem SM. Do Saudi nurses in primary health care centres have breast cancer knowledge to promote breast cancer awareness? Asian Pac J Cancer Prev,2012;4459-64.

30.Abedzade $\mathrm{M}$ et al. study knowledge attitude behavior of breast cancer and screaming women referred to center health in kashan journal scenic research feaze, 2001;(26).

31.Khani H, Moslemizade N, Montazeri A, Godazande Gh, Ghorbani A, Knowledge, attitude $\&$ performance of health care staff about breast cancer prevention programs in southern border of khazar seal ( Caspian sea), Iran breast diseases periodical, 2008;2.

32.Ijazgilani S. et al. Knowledge, attitude and practice of a Pakistani female cohort towards breast cancer. J Pak Med Assoc, 2010; 60(30).

33.Rosmawati NH. Knowledge, attitudes and practice of breast self-examination among women in a suburban area in Terengganu, Malaysia Asian Pac J Cancer Prev,2010;11(6):1503-8

34. Ahmdi Z, et al. Study resent participation about breast cancer screaming and breast cervix women referred to center health in Kerman journal women in reproduce 2010;13(3) 37-46.

35.Saatsaz S. et al. Effect education for knowledge behavior about screaming breast cancer,2009;2(3,4). 